\title{
As Trinta e Seis Vistas do Monte Fuji e a Primeira Consulta de Oncologia
}

\section{Thirty Six Views of Mount Fuji and the First Oncology Appointment}

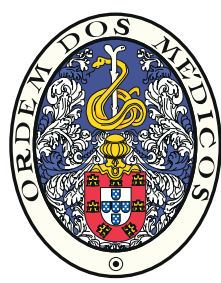

Margarida DANTAS DE BRITO $\triangle 1$

Acta Med Port 2016 Jan;29(1):80-81

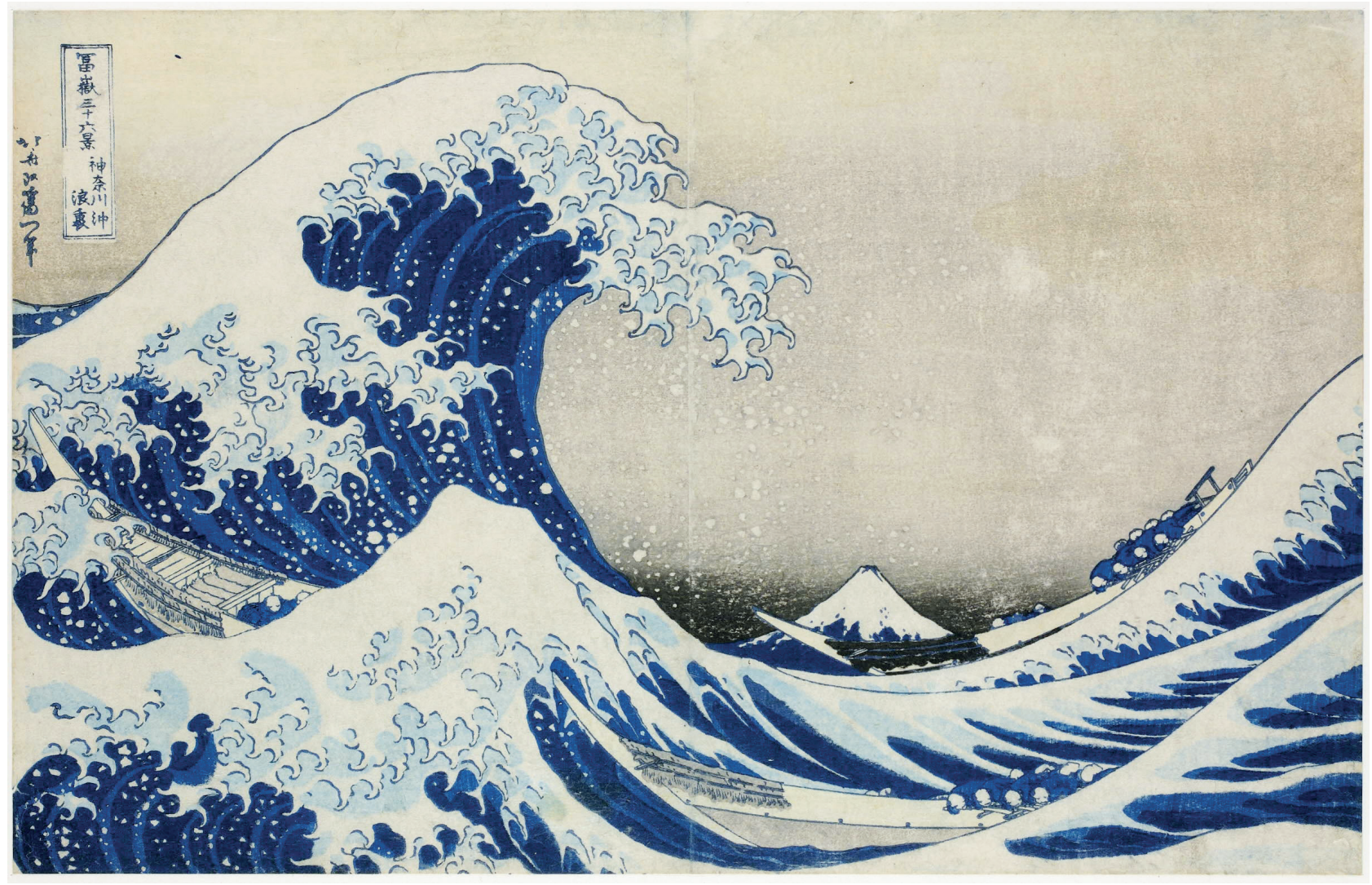

Figura 1 - "A Grande Onda de Kanagawa”, Katsushika Hokusai, 1930-1931, xilogravura, 250 x 370 mm. Fotografia: British Museum.

Palavras-chave: Agendamento de Consultas; Medicina na Arte; Neoplasias; Pintura.

Keywords: Appointments and Schedules; Medicine in Art; Neoplasms; Paintings.

Hokusai (1760-1849) é um dos pintores japoneses mais conhecidos no Ocidente. Destacou-se pelos trabalhos de gravura em placas de madeira, designados por Ukiyo-e. Esta forma de expressão artística é típica e representativa de uma fase da pintura Oriental. ${ }^{1}$ Muitos restaurantes contemporâneos de comida chinesa / japonesa incorporam na sua decoração recriações deste estilo, o que nos remete imediatamente para o imaginário Oriental.

Uma das obras mais famosas de Hokusai é uma série de gravuras que se pensa datarem de 1830 aproximadamente. Representam diferentes vistas do Monte Fuji.
"A Grande Onda de Kanagawa", integra esta série e é o elemento mais célebre. ${ }^{1}$ Nesta gravura o observador encontra um equilíbrio justo entre uma realidade concreta e um espaço metafórico. Está representada a vida dura dos pescadores que enfrentam a imprevisibilidade do mar. Mas não somente. Sente-se o mistério e principalmente uma tensão que remete para algo mais visceral e indefinido. As ondas terminam em forma de garra, são maiores do que o Monte Fuji, local de simbolismo sagrado. ${ }^{1}$ Os pescadores são o elemento mais pequeno, quase impercetível, tragicamente afastados do Monte Fuji. No dinamismo deste

1. Departamento de Hematologia Clínica. Instituto Português de Oncologia Dr. Francisco Gentil do Porto. Porto. Portugal.

$\bowtie$ Autor correspondente: Margarida Dantas de Brito. ana.margarida.dantas@gmail.com

Recebido: 16 de novembro de 2015 - Aceite: 25 de novembro de 2015 | Copyright @ Ordem dos Médicos 2016 
quadro cabem todos os medos. Cabe também a dualidade das primeiras consultas de oncologia, onde tudo é tão concreto - o exame histológico fornece o diagnóstico, o exame imagiológico o estadiamento, segue-se o tratamento. Onde tudo é tão vago, adivinha-se e teme-se uma colisão surda, que fragmenta a pessoa e a transforma num doente. Este, tal como os pescadores, apenas vislumbra vagas de ondas intransponíveis e vê a sua própria dimensão reduzida e afastada do seu local seguro. Todos os intervenientes na consulta, na sua individualidade, viajam nestas ondas. São, afinal, pessoas. Reconhece-se a necessidade de tempo, de silêncio e de fala. E talvez de silêncio novamente. Mas, o mais frequente é que as contingências da realidade hospitalar definam caminhos divergentes para o médico e para o doente: um deriva em informações, o outro, não insensível, foca-se no plano e orienta-o. É insensato da parte do profissional de saúde ambicionar confortar as angústias resultantes de uma situação potencialmente ameaçadora à vida num primeiro contacto, com uma disponibilidade de tempo limitada. No entanto, é urgente tomar conhecimento, valorizar e treinar estratégias de comunicação clínica. As emoções têm algo de intangível e sagrado e, por isso, é fundamental dispor de ferramentas que permitam encontrar o doente no local de onde ele parte. Há um conjunto crescente de literatura científica que discute a comunicação em medicina ${ }^{2-4}$ e modelos facilitadores da entrevista médi$\mathrm{ca}^{4-6}$ que visam optimizar as lacunas do modelo biomédico tradicional. Tem-se tornado evidente que a comunicação não depende da vocação do médico, pode ser aprendida e treinada. ${ }^{2-7}$ Por outro lado, com a implementação destas

\section{REFERÊNCIAS}

1. Cartwright $\mathrm{JH}$, Nakamura $\mathrm{H}$. What kind of wave is Hokusai's great wave of Kanagawa? Notes Rec R Soc. 2009;63:119-35.

2. Kurtz S, Silverman J, Draper J. Teaching and learning communication skills in medicine. $2^{\text {nd }}$ ed. Oxford: Radcliffe Publishing Oxford; 2005.

3. Silverman J, Kurtz S, Draper J. Skills for communicating with patients. $2^{\text {nd }}$ ed. Oxford: Radcliffe Publishing Oxford; 2005.

4. Kurtz S, Silverman J, Benson J, Draper J. Marrying content and process in clinical method teaching: enhancing the Calgary-Cambridge Guides. Academic Medicine. 78:802-9.

5. Aspegren $\mathrm{K}$. Teaching and learning communication skills in medicine-a review with quality grading of articles. Medical Teacher. 1999,21:563-70.

6. Jackson JL, Kroenke K. Difficult patient encounters in the ambulatory clinic: clinical predictors and outcomes. Arch Intern Med. 1999;159:106975. estratégias perdem-se menos informações relevantes do ponto de vista clínico ${ }^{2-4,8}$ e, curiosamente, não parece haver incremento do tempo de consulta. ${ }^{9-11}$

Um comentário em relação ao pigmento predominante nesta obra - o Azul da Prússia (hexacianoferrato férrico). Este pigmento tornou-se popular entre pintores a partir de 1700 por permitir criar tonalidades de azul intenso. ${ }^{12}$ Este composto pode também ser utilizado como medicamento, fazendo parte da lista de medicamentos essenciais da Organização Mundial de Saúde, na classe dos antídotos específicos e agentes utilizados em intoxicações por determinados metais pesados como o Césio e Tálio. ${ }^{13}$ É também importante na imunohistoquímica, designando-se a sua utilização neste contexto como coloração de Perl's. Permite avaliar as reservas de ferro em amostras de medula óssea e a identificação de sideroblástos em anel, achado morfológico característico em alguns subtipos de síndroma mielodisplásico.

\section{AGRADECIMENTOS}

Aos Trustees of the British Museum ${ }^{\odot}$ pela disponibilização da imagem para reprodução sem fins lucrativos.

\section{CONFLITOS DE INTERESSE}

A autora nega a existência de quaisquer conflitos de interesse na realização deste artigo.

\section{FONTES DE FINANCIAMENTO}

A autora não recebeu nenhum financiamento para a escrita do artigo.

7. Elder N, Ricer R, Tobias B. How respected family physicians manage difficult patient encounters. J Am Board Fam Med. 2006;19:533-41.

8. Redelmeier DA. Improving patient care. The cognitive psychology of missed diagnoses. Ann Intern Med. 2005;142:115-20.

9. Langewitz W, Denz M, Keller A, Kiss A, Rüttimann S, Wössmer B. Spontaneous talking time at start of consultation in outpatient clinic: cohort study. BMJ. 2002;325:682-3.

10. Marvel MK, Epstein RM, Flowers K, Beckman HB. Soliciting the patient's agenda: have we improved? JAMA. 1999;281:283-7.

11. Blau JN. Time to let the patient speak. BMJ. 1989;298:39.

12. McCouat P. Prussian blue and it's partner in crime- Jornal of Art in Society; 2012

13. World Health Organization. WHO Model List of Essential Medicines. $19^{\text {th }}$ ed. Geneva: WHO; 2015. 